\title{
Phenotypic effects of subclinical paratuberculosis (Johne's disease) in dairy cattle
}

\author{
Tracey C. Pritchard, ${ }^{* 1}$ Mike P. Coffey, ${ }^{*}$ Karen S. Bond, $†$ Mike R. Hutchings, ${ }^{*}$ and Eileen Wall ${ }^{*}$ \\ *Scotland's Rural College (SRUC), Edinburgh, EH9 3JG, United Kingdom \\ †National Milk Records plc, Chippenham, SN15 1BN, United Kingdom
}

\section{ABSTRACT}

The effect of subclinical paratuberculosis (or Johne's disease) risk status on performance, health, and fertility was studied in 58,096 UK Holstein-Friesian cows with 156,837 lactations across lactations 1 to 3 . Low-, medium-, and high-risk group categories were allocated to cows determined by a minimum of 4 ELISA milk tests taken at any time during their lactating life. Lactation curves of daily milk, protein, and fat yields and protein and fat percentage, together with $\log _{\mathrm{e}}$-transformed somatic cell count, were estimated using a random regression model to quantify differences between risk groups. The effect of subclinical paratuberculosis risk groups on fertility, lactation-average somatic cell count, and mastitis were analyzed using linear regression fitting risk group as a fixed effect. Milk yield losses associated with high-risk cows compared with low-risk cows in lactations 1, 2, and 3 for mean daily yield were 0.34 , 1.05 , and $1.61 \mathrm{~kg}$; likewise, accumulated 305-d yields were 103, 316, and $485 \mathrm{~kg}$, respectively. The total loss was $904 \mathrm{~kg}$ over the first 3 lactations. Protein and fat yield losses associated with high-risk cows were significant, but primarily a feature of decreasing milk yield. Similar trends were observed for both test-day and lactation-average somatic cell count measures with higher somatic cell counts from medium- and high-risk cows compared with low-risk cows, and differences were in almost all cases significant. Likewise, mastitis incidence was significantly higher in high-risk cows compared with low-risk cows in lactations 2 and 3 . Whereas the few significant differences between risk groups among fertility traits were inconsistent with no clear trend. These results are expected to be conservative, as some animals that were considered negative may become positive after the timeframe of this study, particularly if the animal was tested when relatively young. However, the magnitude of milk yield losses together with higher

Received April 15, 2016.

Accepted September 17, 2016.

${ }^{1}$ Corresponding author: Tracey.Pritchard@sac.ac.uk somatic cell counts and an increase in mastitis incidence should motivate farmers to implement the appropriate control measures to reduce the spread of the disease.

Key words: paratuberculosis, Johne's disease, dairy cattle, prevalence

\section{INTRODUCTION}

Paratuberculosis (or Johne's disease), caused by $M y$ cobacterium avium ssp. paratuberculosis (MAP), is a fatal chronic enteritis to which ruminants are particularly susceptible and is responsible for significant efficiency losses in livestock (Raizman et al., 2009) and compromises animal welfare (CHAWG, 2012). Its unproven association with type 1 diabetes (Rani et al., 2010; Naser et al., 2013) and, in particular, Crohn's (Sartor, 2005; Uzoigwe et al., 2007), an incurable disease in humans, could potentially risk the reputation of the agri-food sector (Sartor, 2005; Groenendaal and Zagmutt, 2008). Additionally, MAP can persist in the environment for many months (Whittington et al., 2004) and in a small proportion of cases the organism has been found to survive anaerobic digestion (Slana et al., 2011), water treatment (Aboagye and Rowe, 2011), and pasteurization of milk (Grant et al., 2002), with it being found in retailed milk (C. E. D. Rees, Nottingham University, Nottingham, UK; personal communication) including powdered infant formula (Botsaris et al., 2016). In different regions around the world, increased incidence of Crohn's disease has recently been reported (Molodecky et al., 2012), and although insufficient evidence of a causal link between MAP and Crohn's disease exists, the UK Food Standards Agency has appealed for strategies to further minimize human exposure to MAP (Rubery, 2001).

Paratuberculosis is reported worldwide among cattle populations and is commonly found where significant dairy industry exists. It is considered endemic in Europe and North America, with herd prevalence estimates expected to be higher than 50\% (Nielsen and Toft, 2009; Lombard et al., 2013). Paratuberculosis is considered endemic in the United Kingdom (Carslake et al., 2011) 
and is highly prevalent affecting about three-quarters of dairy cattle herds (Woodbine et al., 2009), which results in significant efficiency losses to the farm business and the dairy industry as a whole, particularly due to reduced milk production as well as reduced slaughter value and premature culling (Raizman et al., 2009; Richardson and More, 2009). Furthermore, the clinical cases are sometimes referred merely as the tip of the iceberg, as it is estimated that at least 25 other animals may be infected with each clinical case born on the farm (Whitlock and Buergelt, 1996). The main source of MAP infection is the fecal-oral route, as it is mostly excreted in feces (although it can also be shed in colostrum, milk, and semen) and can be transmitted through contaminated teats, bedding, pasture, soil, or water. Spread of MAP mostly occurs from infected adults to newborns, who are most susceptible to infection (Windsor and Whittington, 2010). However, due to a long incubation period, the disease is largely subclinical in domesticated livestock, with clinical disease manifesting not until 2 or more years after infection, with it taking place earliest via vertical transmission (i.e., transplacental) where dams were advanced in the disease (Windsor and Whittington, 2010). Nevertheless, economic losses are also expected before clinical signs taking place (Benedictus et al., 1987; Nielsen et al., 2009).

At present, no cure exists for MAP; therefore, control strategies are based upon timely detection through testing and culling of infected animals together with good hygiene practices to reduce transmission. In some countries, voluntary Johne's control programs have been established (Benedictus et al., 2000; Nielsen, 2007; Bartlett and Pearse, 2012); however, due to the latency and slow progression of the infection together with the lack of accurate diagnostic tests, diagnosis of MAP infection can prove challenging, being particularly difficult to identify infected cattle in the early stages. Thus, herd prevalence is expected to be underestimated, particularly when animals are tested or culled at a relatively young age; consequently, clinical cases may not be seen within the lifespan of the animal. Several diagnostic tests exist, but they differ in their sensitivity, specificity, cost, and practicality. Repeated testing over time is valuable for the detection of paratuberculosis due to the progression of the disease in infected animals, and testing tends to be more effective in the later stages of disease.

Since the introduction of various diagnostic tests for MAP, many studies have reported efficiency losses associated with the disease. However, the magnitude of losses reported in the literature are wide ranging and sometimes conflicting. For instance, milk production losses range from 2 (Tiwari et al., 2007) to $18 \%$
(Spangler et al., 1992), which results in large variation in estimates of the costs of the disease. Previous studies on UK cattle diseases have indicated paratuberculosis to be of less importance in terms of costs when compared with other major endemic diseases (Bennett and Ijpelaar, 2005; Stott et al., 2005).

Until recently, reliable national disease data in the UK have been scarce (Bennett and Ijpelaar, 2005), and studies on the effect of paratuberculosis that require prevalence estimates or the magnitude of efficiency losses have been confined to small geographical regions (Woodbine et al., 2009; Beasley et al., 2011) or based their assumptions on estimates from other countries. To a certain degree, losses associated with paratuberculosis are related to the production system; therefore, results obtained in one country may not necessarily be applied to another. However, with the recent introduction of a voluntary control program for paratuberculosis in the UK, the volume of data has increased year by year and is now sufficient for analysis. It is probable that these tests would be used to identify animals with subclinical paratuberculosis rather than clinically affected animals that would be displaying signs of the disease. The objective of the current study was to estimate the effect of a subclinical paratuberculosis risk group based upon milk ELISA measurements in terms of efficiency losses related to production, fertility, and udder health.

\section{MATERIALS AND METHODS}

Testing milk samples for paratuberculosis (Johne's disease) is a service available to farmers in the United Kingdom through National Milk Records (NMR) via the commercial milk ELISA Idexx Pourquier Mycobacterium paratuberculosis Screening Antibody Test (Idexx Laboratories Inc., Westbrook, ME; Bartlett and Pearse, 2012). Herds enrolled in the paratuberculosis-control program have their milking cows tested quarterly during routine herd recording. Test results of milk ELISA from a 5-yr period, 2007 to 2012, were obtained from NMR for 2,197 UK herds. Routinely recorded production and SCC, fertility, and health records were also obtained from NMR.

Most infected cows produce antibodies, and it is reported that repeated ELISA testing before 350 DIM is the best method to capture infected animals (Nielsen and Ersbøll, 2006). The use of single tests per animal can lead to higher false-negative results, which could misclassify an infected animal, as an animal may change infection status during a period of testing. Therefore, cows were classified into low- (LR), medium- (MR), and high-risk (HR) groups based upon combined test results from a minimum of 4 samples, as defined in Table 1 and derived upon simplified categories of 
Table 1. Definition of risk group categories

\begin{tabular}{ll}
\hline Risk group & Definition \\
\hline Low (LR) & All tests negative; 1 test positive but last test negative (perhaps was a false positive) \\
Medium (MR) & Last test positive; at least 2 tests positive but not adjacent tests \\
High (HR) & At least 2 adjacent tests positive (even if a negative test has followed) \\
\hline
\end{tabular}

Nielsen (2007). The risk groupings are in line with the color classification used to guide farmers for diseasemanagement purposes, where green, amber, and red represent low, medium, and high risk. The ELISA tests were categorized as positive if the sample-to-positive control ratio was 0.3 or higher. Risk categories were assigned based upon all tests after the last test of an animal. Once an animal was allocated to a high-risk group it stayed in that category. Similar to the methodology of Marcé et al. (2009), the lactation of the last test at which animals were allocated to risk groups had no bearing and animals were considered to be either LR, MR, or HR from their first lactation onwards. Thus, even if an animal had no positive tests in its first lactation it could be allocated as HR in its first lactation due to positive tests in a later lactation. This approach was adopted because most infections begin at or shortly after birth (Windsor and Whittington, 2010), and potential effects on production, udder health, and fertility could take place before detection of subclinical paratuberculosis by means of a test.

\section{Data Editing}

Test day (TD) milk yield (MY; $\mathrm{kg}$ ), protein yield $(\mathbf{P Y} ; \mathrm{kg})$, protein yield percentage (PY\%), fat yield (FY; kg), fat yield percentage (FY\%), and SCC data were obtained for all available TD during lactations 1 to 3 on Holstein Friesian cows that had milk ELISA tests performed anytime during their life (including lactation $4+)$. Thus, lactations were analyzed that did not necessarily have milk ELISA tests in the same lactation. The following edits were used for the final analysis: (1) all tests of an animal took place in 1 herd only, and herds included had at least 2 positive tests; (2) calving ages for lactations 1,2 , and 3 were 18 to 42,30 to 56 , and 42 to 70 mo; (3) at test cows were 4 to 305 DIM; (4) weight of milk at test was between 5 and $60 \mathrm{~kg}$ and $\leq 3$ standard deviations from the mean milk yield within DIM and lactation number; and (5) at least 5 animals were included per milk herd TD. After editing, the data set consisted of 58,096 cows with 156,837 lactations with 1,350,928 TD records, born between 2002 and 2009, and calved between 2007 and 2012 from 561 herds. A summary of TD data counts are given in Table 2. Overall, $13.7 \%$ of animals were allocated as MR or HR in the data set. Three further subsets were created on first-lactation data based upon the lactation number (1-3) in which risk group was determined. For instance, T1, T2, and T3 subsets contained animals that had their risk category determined in lactation 1,2 , and 3 (i.e., $\mathrm{T} 1=$ animals that had their last milk ELISA tests in lactation 1 had risk group determined in lactation 1). This was done to explore the differences in production levels between animals of the same risk group, but determined at a different stage of life.

In addition to TD data, the effect of the subclinical paratuberculosis risk group on fertility and udder health was studied by analysis of the following traits where validated data were available: $\log _{\mathrm{e}}$-transformed lactation somatic cell count (LSCC), the binary trait clinical mastitis (MAS; $0=$ not affected, $1=$ affected with clinical mastitis at least once within 0 and 305 DIM), calving interval (CaI), the binary trait nonreturn rate at $56 \mathrm{~d}$ (NR56; 1 = failure, 2 = success), days to first service (DFS), and number of inseminations (NINS). The LSCC was restricted to lactations with at least 6 tests, and from these the mean was taken and log-transformed. The recording of MAS was undertaken by farmers on a voluntary basis as part of

Table 2. Summary of the number of milk tests grouped by lactation number and risk group

\begin{tabular}{lccccc}
\hline & & & \multicolumn{3}{c}{ No. of cows (tests) } \\
\cline { 4 - 6 } Lactation & \multirow{2}{*}{$\begin{array}{c}\text { No. of lactations } \\
\text { (tests) }\end{array}$} & $\begin{array}{c}\text { Mean no. } \\
\text { of tests/cow }\end{array}$ & Low risk & Medium risk & High risk \\
\hline 1 & 52,330 & 8.7 & 45,224 & 4,360 & 2,746 \\
& $(456,390)$ & & $(394,161)$ & $(38,216)$ & $(24,013)$ \\
2 & 54,238 & 8.7 & 46,849 & 4,540 & 2,849 \\
& $(473,276)$ & & $(408,985)$ & $(39,732)$ & $(24,559)$ \\
3 & 50,269 & 8.4 & 43,418 & 4,262 & 2,589 \\
& $(421,262)$ & & $(363,663)$ & $(36,074)$ & $(21,525)$ \\
\hline
\end{tabular}


Table 3. Descriptive statistics of udder health and fertility traits

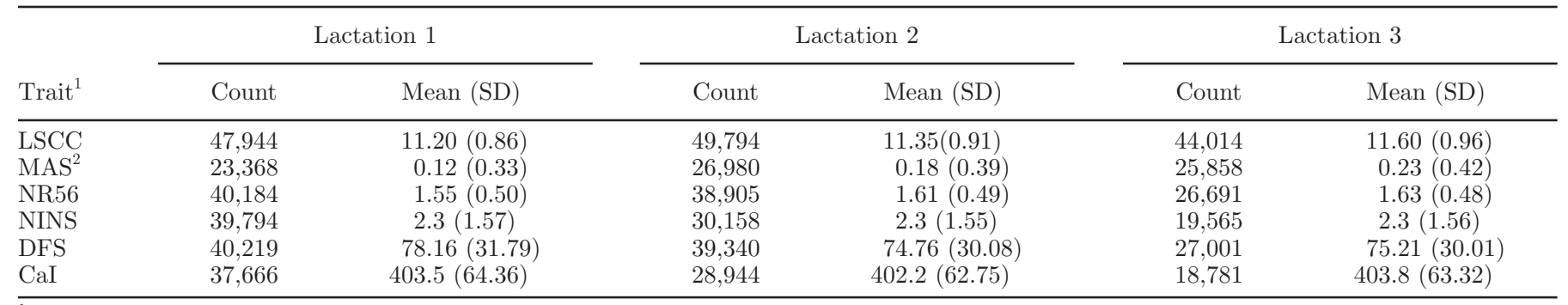

${ }^{1} \mathrm{LSCC}=$ lactation average $\log _{\mathrm{e}}$-transformed SCC; MAS $=$ mastitis (binary trait: $0=$ no mastitis and $1=$ infected with mastitis at least once within 0 to 305 DIM); NR56 = nonreturn rate after $56 \mathrm{~d}$ (binary trait: $1=$ a return to service and $2=$ no return to service); NINS $=$ number of inseminations per conception (maximum of 10 inseminations); DFS = days to first service, number of days from calving date of present lactation to date of first service; $\mathrm{CaI}=$ calving interval: number of days from calving date of present lactation to calving date of next lactation.

${ }^{2}$ Consider trait mean as a ratio of number of cows affected.

routine milk recording and the data were made available by NMR. The definition of MAS is explained in detail in Pritchard et al., (2013). For editing of fertility traits, CaI was restricted between 300 and $600 \mathrm{~d}$, DFS was not less than $20 \mathrm{~d}$ and not greater than 200 DIM, and 10 or more inseminations until conception were grouped as 10 for NINS. Further editing required at least 3 animals in the herd-year-season contemporary group for each trait measurement. Descriptive statistics of udder health and fertility traits are shown in Table 3.

\section{Data Analysis}

All phenotypic analyses of production, health, and fertility traits were analyzed in ASReml (Gilmour et al., 2006). For all TD models [MY, PY, FY, PY\%, FY\%, and $\log _{\mathrm{e}}$-transformed SCC (TSCC)] the mean trajectory of the population was modeled for the LR, $\mathrm{MR}$, and HR group categories using a random regression model with orthogonal Legendre polynomials of order 4 for DIM. In the matrix form, the model is given by equation 1 :

$$
\mathbf{y}=\mathbf{X b}+\mathbf{Z u}+\mathbf{e}
$$

where $\mathbf{y}$ is the vector of observations (MY, PY, FY, $\mathrm{PY} \%, \mathrm{FY} \%, \mathrm{TSCC})$; $\mathbf{b}$ is the vector of fixed effects consisting of age at calving (in months), year of calving, breed effects heterosis and recombination (as covariates due to the varying combination of Holstein and Friesian genes), Legendre polynomial of order 4 for DIM (fitted as a covariate 4 to $305 \mathrm{~d}$ ) within risk group (LR, $\mathrm{MR}, \mathrm{HR}) ; \mathbf{u}$ is the vector of random coefficients for the contemporary group herd-test-day (effect specific to all cows on the same TD within a herd) and the permanent environment effect of the animal (as there are several records per animal); $\mathbf{X}$ and $\mathbf{Z}$ are the incidence matrices for fixed effects and random effects, respec- tively; and $\mathbf{e}$ is the vector of residual effects. Residual variances for 10 classes were estimated according to lactation stage, namely 4 to 29,30 to 59,60 to 89,90 to 119,120 to 149,150 to 179,180 to 209,210 to 239,240 to 269 , and 270 to 305 DIM. Heterosis and recombination loss, which considered only 2 breeds (Holstein and Friesian), were calculated as shown in equations 2 and 3 (Wall et al., 2005):

$$
\text { heterosis }=\mathrm{P}_{\mathrm{S}}\left(1-\mathrm{P}_{\mathrm{D}}\right)+\mathrm{P}_{\mathrm{D}}\left(1-\mathrm{P}_{\mathrm{S}}\right) \text {, }
$$

and

$$
\text { recombination loss }=\mathrm{P}_{\mathrm{D}}\left(1-\mathrm{P}_{\mathrm{D}}\right)+\mathrm{P}_{\mathrm{S}}\left(1-\mathrm{P}_{\mathrm{S}}\right) \text {, [3] }
$$

where $\mathrm{P}_{\mathrm{S}}$ and $\mathrm{P}_{\mathrm{D}}$ are the proportion of Holstein for the sire and dam, respectively.

The model used for analysis of a single parity for LSCC, MAS, CaI, DFS, NR56, or NINS included risk group (LR, MR, and HR) fitted as a fixed effect. Further fixed effects were tested in SAS software (SAS Institute, 2006) and based upon those used in genetic analyses of the above traits (Pritchard et al., 2013) excluding any genetic component as shown by equation 4 :

$$
\begin{gathered}
\mathrm{Y}_{\mathrm{ijk}}=\mu+\operatorname{riskGrp}_{\mathrm{i}}+\text { month }_{\mathrm{j}}+\beta_{1} \mathrm{X}_{\mathrm{het}} \\
+\beta_{2} \mathrm{X}_{\mathrm{rec}}+\beta_{3} \mathrm{X}_{\text {age }}+\beta_{4}\left(\mathrm{X}_{\text {age }}\right)^{2}+\text { hys }_{\mathrm{k}}+\mathrm{e}_{\mathrm{ijk}},
\end{gathered}
$$

where $Y_{\mathrm{ijk}}=$ is an observation for LSCC, MAS, or fertility; $\mu$ is the overall mean of trait $Y$; $\operatorname{riskGrp}_{\mathrm{i}}=$ fixed effect of the ith risk group ( 3 groups); month $_{\mathrm{j}}=$ fixed effect of the jth month of calving (12 mo); $\beta_{1}$ to $\beta_{4}=$ linear and quadratic regression coefficients of dependent variable $\mathrm{Y}$ on heterosis $\left(\mathrm{X}_{\text {het }}\right)$, recombination $\left(\mathrm{X}_{\mathrm{rec}}\right)$, age at calving $\left(\mathrm{X}_{\text {age }}\right)$; hys $\mathrm{s}_{\mathrm{k}}=$ the random effect of herdby-year-by-season; and $\mathrm{e}_{\mathrm{ijk}}=$ residual random error term. The repeatability model that analyzed the first 
Table 4. The effect of subclinical paratuberculosis risk group on mean milk yield (mean \pm SE)

\begin{tabular}{|c|c|c|c|}
\hline \multirow[b]{2}{*}{ Item $^{1}$} & \multicolumn{3}{|c|}{ Paratuberculosis risk group } \\
\hline & Low risk & Medium risk & High risk \\
\hline \multicolumn{4}{|l|}{ Lactation 1} \\
\hline ADMY (kg) & $24.5 \pm 0.06$ & $24.4 \pm 0.22$ & $24.2 \pm 0.28$ \\
\hline LMY (kg) & $7,398.0 \pm 19.17$ & $7,367.7 \pm 67.36$ & $7,295.1 \pm 85.86$ \\
\hline DEV_LR (kg/d) & $0.00^{\mathrm{a}}$ & $-0.10 \pm 0.08$ & $-0.34^{\mathrm{a}} \pm 0.09$ \\
\hline \multicolumn{4}{|l|}{ Lactation 2} \\
\hline ADMY (kg) & $26.7 \pm 0.22$ & $26.3 \pm 0.44$ & $25.7 \pm 0.49$ \\
\hline LMY $(\mathrm{kg})$ & $8,061.7 \pm 65.57$ & $7,941.2 \pm 132.75$ & $7,745.7 \pm 146.80$ \\
\hline DEV_LR $(\mathrm{kg} / \mathrm{d})$ & $0.00^{\mathrm{ab}}$ & $-0.40^{\mathrm{a}} \pm 0.10$ & $-1.05^{\mathrm{b}} \pm 0.12$ \\
\hline \multicolumn{4}{|l|}{ Lactation 3} \\
\hline ADMY $(\mathrm{kg})$ & $30.8 \pm 0.28$ & $30.1 \pm 0.51$ & $29.2 \pm 0.56$ \\
\hline LMY (kg) & $9,314.3 \pm 83.25$ & $9,098.3 \pm 154.09$ & $8,828.9 \pm 170.02$ \\
\hline DEV_LR (kg/d) & $0.00^{\mathrm{ab}}$ & $-0.72^{\mathrm{a}} \pm 0.11$ & $-1.61^{\mathrm{b}} \pm 0.13$ \\
\hline
\end{tabular}

3 lactations together also included lactation number. Convergence was reached for each analysis and $t$-tests were carried out to determine the significance of differences $(P \leq 0.05)$ of predicted means between pairwise comparisons of subclinical paratuberculosis risk groups.

\section{RESULTS}

Prior to data editing, $76 \%$ of the initial 2,197 herds had at least 1 ELISA-positive test, and $67 \%$ of the herds had at least 2 positive tests during the testing period in years 2007 to 2012 . However, in the $63 \%$ of herds with at least 50 tested animals it was found that 97 and $93 \%$ of these had at least 1 and 2 ELISA-positive tests, respectively. Overall, $10.2 \%$ of animals had at least 1 ELISA-positive test, and this increased to $11.0 \%$ if including only herds with at least 2 ELISA-positive tests as carried out in the data edits. For herds with at least 2 ELISA-positive tests, the number of positive tests by lactation number increased from $4.2 \%$ in lactation 1 to $7.1 \%$ in lactation 5 .

\section{Production}

The accumulated 305-d yields for production traits were calculated from daily yield estimates from 4 to 305-d for the LR, MR, and HR group categories, as reported in Tables 4 and 5. For lactations 1 to 3, the MR and HR groups were associated with reduced MY, PY, and FY, and as yield increased with lactation number the magnitude of the yield differences between LR with $\mathrm{MR}$ and HR groups also increased. Results from the MR group were intermediate between LR and HR, and further reporting of results will concentrate on differences between LR and HR. The mean cumulative losses of MY, PY, and FY from HR cows were -904.4, -27.1, and $-34.0 \mathrm{~kg}$, respectively, summed over the first 3 lactations. For MY, mean daily losses from HR cows compared with LR cows for lactations 1, 2, and 3 were $-0.3,-1.1$, and $-1.6 \mathrm{~kg}$, respectively, over the period from 4 to 305 d. In terms of percentage losses, these generally increased with DIM (Figure 1) and mean MY losses were $-1.4,-4.2$, and $-5.5 \%$ for lactations 1,2 , and 3 respectively. From 3 subsets, T1, T2, and T3, which comprised first-lactation data, the milk yield losses from 4 to $305 \mathrm{~d}$ were $-4.8,-2.1$, and $-1.6 \%$, respectively, when comparing $\mathrm{HR}$ cows to LR cows.

A reduction in MY is understandably accompanied with losses of PY and FY, as shown in Table 5. A significant reduction in mean daily PY and FY for the MR and HR groups were observed compared with LR in lactations 1 to 3 together with significant differences observed between MR and HR in lactations 2 and 3. Losses tended to increase with DIM, and overall lactation losses from HR cows compared with LR cows for PY were 1.3, 3.7, and 4.9\% and for FY were 1.4, 4.0, and $5.5 \%$ for lactations 1,2 , and 3 , respectively. However, significant differences were only observed between LR and MR in lactation 3 for average daily PY\% and in lactations 1 and 2 for FY\%, with higher PY\% and FY\% observed in MR cows.

\section{SCC}

Lactation curves estimated from random regression (Figure 2) showed that TSCC tended to be higher in MR and HR cows, particularly in lactations 2 and 3, and overall differences between LR, MR, and HR cows were significant in all cases (Table 5). Similarly, the linear model analysis of LSCC showed in all cases that 


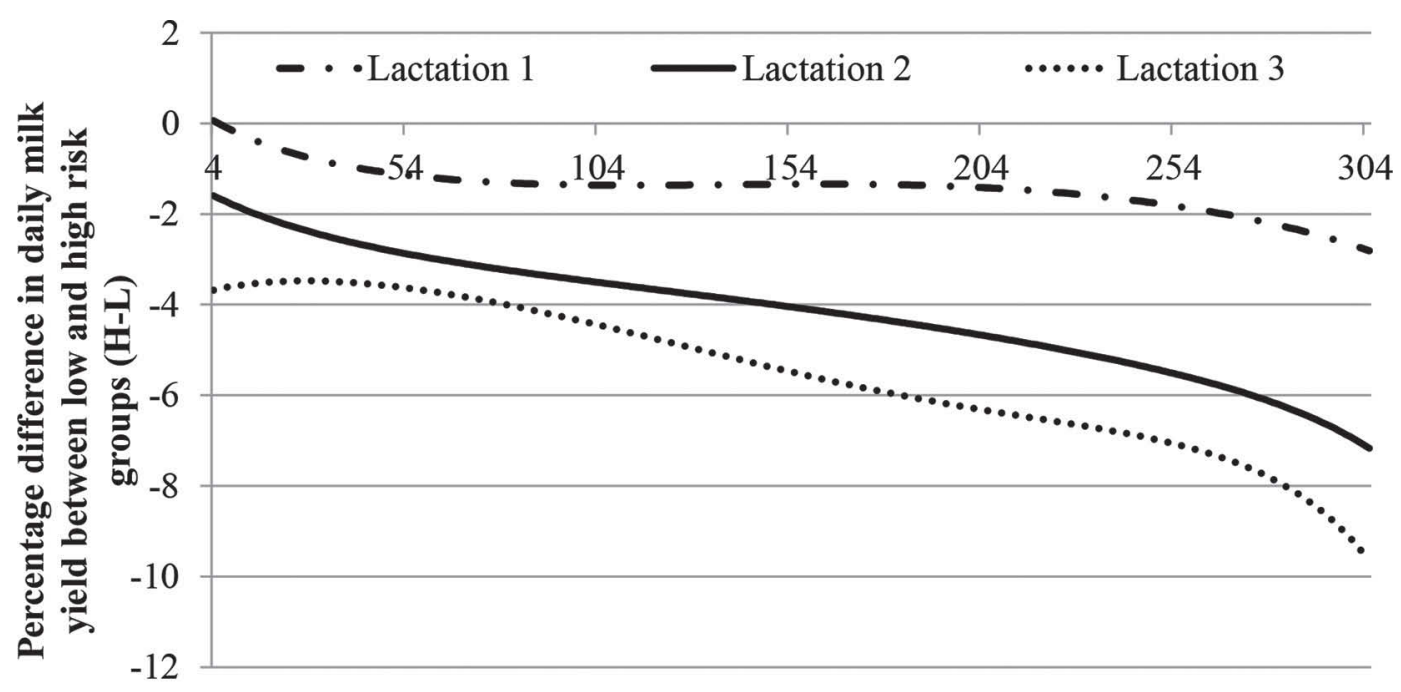

Days in milk

Figure 1. Percentage difference in daily milk yield of the high-risk group cows (H) compared with the low-risk group cows (L) in lactations 1 to 3 .

both the MR and HR groups had a significantly higher LSCC than LR cows, with the exception of MR in lactation 1 (Table 6).

\section{Mastitis}

Predicted incidence levels of MAS were greater in HR cows compared with the LR and MR groups, but not all differences between risk groups were significant. In lactation 2, MR and HR cows had significantly higher incidence than LR cows and HR cows had significantly higher incidence than MR cows. When MAS was analyzed as a repeated trait across lactations 1 to 3 predicted incidence levels were 19, 20, and $21 \%$ for the LR, MR, and HR groups, respectively, with significant differences between LR and HR.

Table 5. The effects of subclinical paratuberculosis risk group on mean test day milk composition and log-transformed SCC (with SE in parentheses) $)^{1}$

\begin{tabular}{|c|c|c|c|c|}
\hline Trait & Lactation & \multicolumn{3}{|c|}{ Subclinical paratuberculosis risk group } \\
\hline \multirow[t]{3}{*}{ PY (kg) } & 1 & $0.76^{\mathrm{a}}(0.024)$ & $-0.002^{\mathrm{b}}(0.002)$ & $-0.009^{\mathrm{ab}}(0.003)$ \\
\hline & 2 & $0.90^{\mathrm{ab}}(0.026)$ & $-0.01^{\mathrm{ac}}(0.003)$ & $-0.03^{\mathrm{bc}}(0.003)$ \\
\hline & 3 & $1.04^{\mathrm{ab}}(0.035)$ & $-0.02^{\text {ac }}(0.003)$ & $-0.05^{\mathrm{bc}}(0.004)$ \\
\hline FY (kg) & 3 & $1.15^{\mathrm{ab}}(0.035)$ & $-0.022^{\mathrm{ac}}(0.004)$ & $-0.061^{\mathrm{bc}}(0.005)$ \\
\hline \multirow[t]{3}{*}{ PY\% } & 1 & $3.16(0.029)$ & $0.006(0.003)$ & $0.002(0.004)$ \\
\hline & 2 & $3.42(0.030)$ & $0.006(0.004)$ & $0.005(0.004)$ \\
\hline & 3 & $3.45^{\mathrm{a}}(0.031)$ & $0.008^{\mathrm{a}}(0.004)$ & $0.003(0.005)$ \\
\hline \multirow[t]{3}{*}{ FY\% } & 1 & $3.88^{\mathrm{a}}(0.051)$ & $0.017^{\mathrm{a}}(0.002)$ & $-0.0003(0.009)$ \\
\hline & 2 & $3.99^{\mathrm{a}}(0.051)$ & $0.018^{\mathrm{a}}(0.008)$ & $0.002(0.010)$ \\
\hline & 3 & $3.93(0.053)$ & $0.014(0.008)$ & $-0.001(0.010)$ \\
\hline
\end{tabular}

${ }^{\mathrm{a}-\mathrm{c}}$ Means within a row with shared superscript letters were significantly different from each other $(P<0.05)$.

${ }^{1} \mathrm{LR}=$ low risk; $\mathrm{MR}=$ medium risk; $\mathrm{HR}=$ high risk; $\mathrm{PY}=$ protein yield $(\mathrm{kg}) ; \mathrm{FY}=$ fat yield $(\mathrm{kg}) ; \mathrm{PY} \%=$ protein yield percentage; FY\% $=$ fat yield percentage; TSCC $=\log _{\mathrm{e}}$-transformed lactational SCC. 
Table 6. Predicted means for subclinical paratuberculosis risk group categories for udder health and fertility traits (SE in parentheses) ${ }^{1}$

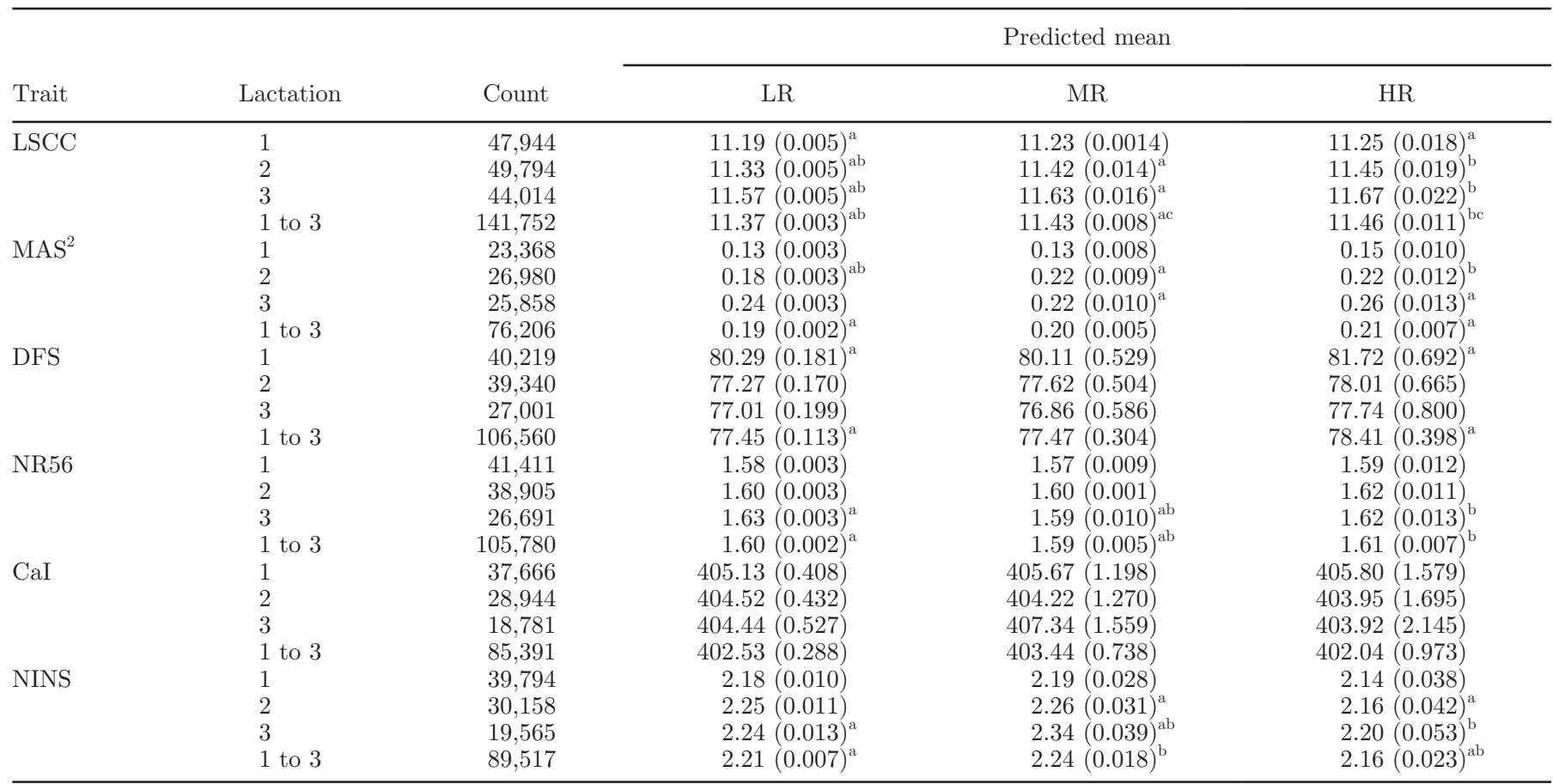

${ }^{\mathrm{a}-\mathrm{C}}$ Within a row, shared superscript letters show that values are significantly different from each other $(P<0.05)$.

${ }^{1} \mathrm{LR}=$ low risk; $\mathrm{MR}=$ medium risk; $\mathrm{HR}=$ high risk; $\mathrm{LSCC}=$ lactation-average $\log _{\mathrm{e}}$-transformed SCC; MAS = mastitis $($ binary trait: $0=$ no mastitis and $1=$ infected with mastitis at least once within 0 to 305 DIM); NR56 = nonreturn rate after 56 d (binary trait: $1=$ a return to service and $2=$ no return to service); NINS = number of inseminations per conception (maximum of 10 inseminations); DFS $=$ days to first service, number of days from calving date of present lactation to date of first service; CaI = calving interval (number of days from calving date of present lactation to calving date of next lactation).

${ }^{2}$ Consider trait mean as a ratio of number of cows affected.

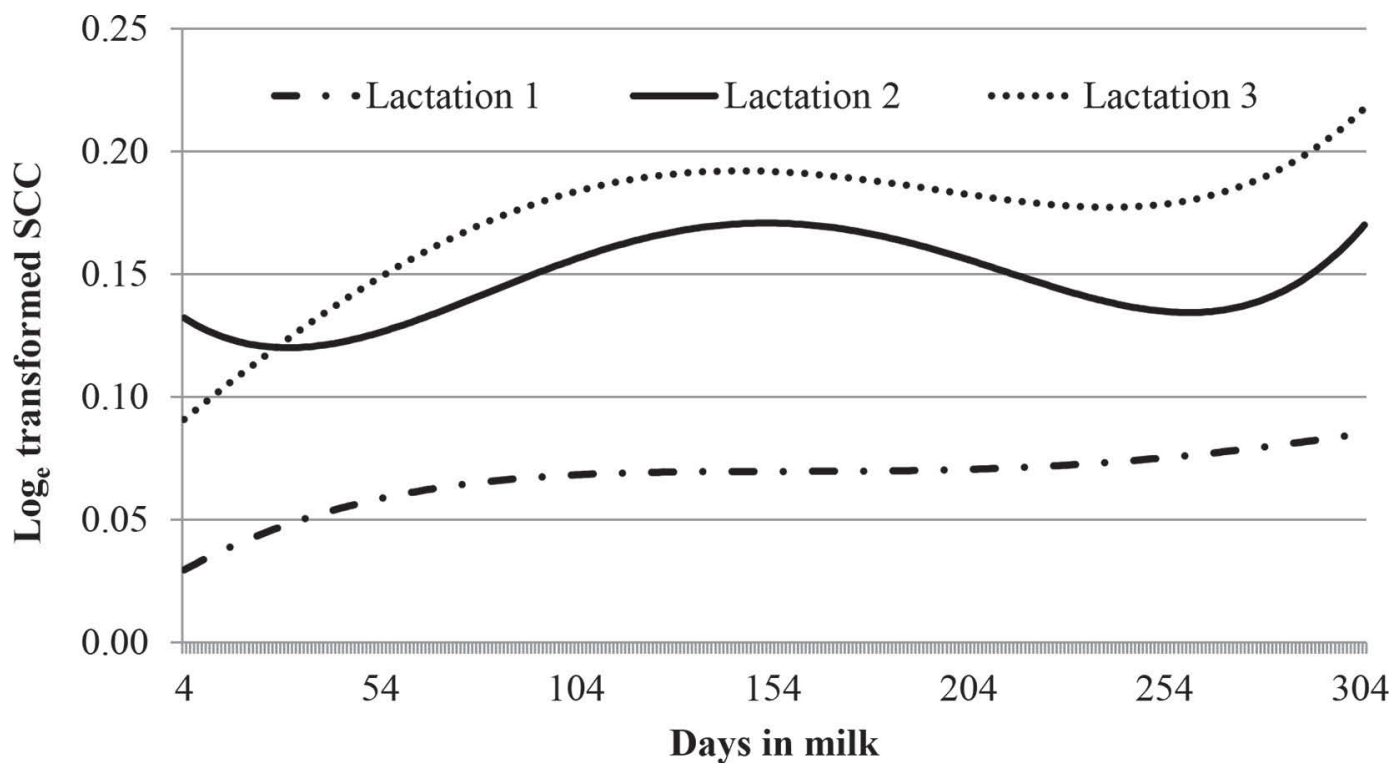

Figure 2. Daily differences in $\log _{\mathrm{e}}$-transformed SCC in the high-risk group cows compared with the low-risk group cows in lactations 1 to 3 . 


\section{Fertility}

We found no significant differences between predicted means of CaI, but some significant associations were found between paratuberculosis risk groups for NINS, NR56, or DFS, as shown in Table 6. The DFS increased with increased level of risk, but the difference was only significant between LR (80.3 d) and HR (81.7 d) in lactation 1 and the repeatability model (containing all 3 lactations). It appeared that MR cows were more likely to return to service after $56 \mathrm{~d}$ than LR or HR cows, which was significant in lactation 1 and as a repeatability model. In lactation 3 , NINS were significantly fewer in HR cows than LR cows and MR cows required significantly more inseminations than LR and HR cows.

\section{DISCUSSION}

This study estimated that $76 \%$ of the 2,197 tested herds had at least 1 cow with an ELISA-positive test, which support the findings of Woodbine et al. (2009), who found that $75-78 \%$ of tested dairy herds had at least one ELISA-positive test through serum ELISA testing in southwest England. Similarly, $10.1 \%$ of cattle with at least 1 ELISA-positive test (Woodbine et al., 2009 ) is close to our findings of $10.2 \%$. Although, at an animal level, the percentage of positive tests is relatively low and it is important to consider the limitations of the antibody ELISA with low sensitivity, particularly in the early stages of the disease; hence, not all infected animals are uncovered. Therefore, several studies have suggested that their herd prevalence estimates are likely to be underestimated (Woodbine et al., 2009; Beasley et al., 2011). In another UK study, $2.5 \%$ of dairy cows ( $\geq 3$ yr old) were ELISA-positive and $65 \%$ of herds had at least 1 ELISA-positive cow (Anon, 2009). Earlier UK studies (Çetinkaya et al., 1996, 1998) reported lower prevalence estimates from both a survey of dairy farmers ( $17.4 \%$ of herds with at least 1 case of disease) and an abattoir-based study (3.5\% of adult cattle with subclinical disease). The survey of farmers considered only clinical cases; therefore, the prevalence of MAP infections would be expected to be higher, as clinical disease affects a fraction of those animals infected at one time. The data set in the current study could be described as self-selecting, as it is unlikely that herds without a paratuberculosis issue would undertake quarterly whole-herd testing. Therefore, we cannot say that these results are representative for the United Kingdom at a national level, but they are anticipated to be very similar, with mean statistics for performance parameters close to those used in an earlier study using a subset extracted from the 2 main UK milk recording organizations (Pritchard et al., 2013).
In countries with a significant dairy industry, estimates of herds affected with paratuberculosis were $10 \%$ in the early 1990s and 30 to $50 \%$ in early 2000s (Barkema et al., 2010). It is difficult to compare prevalence estimates across studies in different countries due to differences in diagnostic tests, the age profile of tested animals, the frequency of testing, and the thresholds used to indicate disease (Nielsen, 2007; Nielsen and Toft, 2009; Kirkeby et al., 2015). As with other studies (Kudahl et al., 2004; Woodbine et al., 2009), we found that the incidence of ELISA-positive tests increased with age. This can be explained by the long incubation period of paratuberculosis; thus, the production of detectable antibodies with advancement of the infection cycle is likely in older cows. Prevalence estimates between studies are likely to differ when they contain varying age structures.

\section{Analysis of Risk Groups}

Results from our study indicate that HR cows were associated with detrimental effects on production and health. Conservative estimates were expected, as some animals considered negative here might become positive after the period studied, particularly if at testing the animal was relatively young. Single milk ELISA tests are not as sensitive as other diagnostic tests for MAP, but ELISA is widely used for practical reasons, as it is minimally invasive, low-cost, and gives a rapid turnaround of results; our study benefitted by the volume of data available. The high specificity but low sensitivity of the diagnostic test means that a very small proportion of noninfected animals could be falsely classified as positives and a higher proportion of infected animals could be falsely classified as negatives; thus, the effects are likely to be underestimated. However, the quarterly testing of animals gives a better overall sensitivity.

\section{Milk Yield}

Our results suggest that subclinical paratuberculosis infection is associated with reduced MY, which is in agreement with previous reports. A decrease of 103 to $485 \mathrm{~kg}$ (equivalent to 1.4 to $5.5 \%$ ) was estimated from 4 to 305 DIM, depending on lactation number, and these losses are consistent with other studies. However, reported estimates have been inconsistent because results are influenced by factors such as parity, lactation stage, stage of disease, prevalence of the herd, and the choice of diagnostic test used. Johnson et al. (2001) reported no association between test status and production, whereas results of studies reporting milk losses from infected cows are wide ranging, from 2 (Tiwari et al., 2007) to $18 \%$ (Spangler et al., 1992). 
Two other studies that used milk ELISA testing have comparable results, with losses from positive cows ranging from 3 to $7 \%$ compared with negative cows (Hendrick et al., 2005; Sorge et al., 2011). Likewise, milk yield losses of $4 \%$ in serum ELISA-positive animals compared with serum ELISA-negative animals reported by Nordlund et al. (1996) are of similar magnitude to our study. The magnitude of the yield differences between LR with MR and HR increased with parity, which would be expected because the disease has a long incubation period and infection is likely to be more advanced in later lactations. In our study, milk losses were apparent in lactation 1 from MR or HR cows, yet not all studies have found an association in early parities (Tiwari et al., 2007; Aly et al., 2010). Aly et al. (2010) found that the association between MAP and milk production was not significant in lactation 1 but increased as cows progressed to higher lactations, whereas Tiwari et al., (2007) found no association between MAP and lower milk yield until lactations 4 or greater.

Some studies have revealed that infected cows may not always show the expected production losses compared with noninfected herdmates, but in fact express higher yields earlier in life before testing positive (Nielsen et al., 2009; Smith et al., 2009; Sorge et al., 2011). For instance, Sorge et al. (2011) found that lowpositive cows during their second lactation exceeded $218 \mathrm{~kg}$ more than negative herdmates in their first lactation. Relatedly, Hoogendam et al. (2009) found that positive herds tended to have higher breeding values for milk yield. Those studies may indicate that cows capable of producing higher yields might be more prone to paratuberculosis infection, but their milk yield does not suffer greatly at early stages of the infection; this would explain the inconsistencies among studies. In addition, this might suggest that the management of high-yielding cows is leading to greater transmission risk, and therefore higher levels, of disease. Further analysis in our study revealed that animals allocated as high risk early in life (i.e., in lactation 1) were associated with greater losses than animals allocated as high risk at a later stage, which was similarly observed by Gonda et al. (2007). It would be expected that animals infected with a higher dose of MAP would have more rapid disease progression and therefore test positive and suffer lower yields at an earlier stage. Stressors on the cow could possibly play a part on how quickly a cow tests positive and becomes clinically affected. Therefore, higher yielders (i.e., more stressed, in negative energy balance) might be more likely to become positive and affected in their lifetime. It has been suggested that cows staying in the herd with 3 or more lactations could be better at coping with infection (Kudahl et al.,
2004) or possibly are under less stress and therefore do not suffer such great losses. In addition, it is likely that bias existed in our study, as the worst-affected animals would be culled before their third lactation and the test itself as part of a control program for paratuberculosis would lead to the culling of high-risk animals.

\section{Protein and Fat Yields}

In this study significant decreases in PY $(9.03 \mathrm{~kg} /$ lactation) and FY (11.32 kg/lactation) were associated with paratuberculosis infection, which were in line with the results of Gonda et al. (2007), who reported significant decreases of 9.49 and $11.46 \mathrm{~kg} /$ lactation for PY and FY. However, the decreases in PY and FY are likely to be a feature of decreasing MY, as revealed when MY was included in the model for analysis for PY and no significant differences between risk groups were found. We observed that protein and fat percentages tended to be higher in MR and HR cows, but only MR cows in lactations 1 and 2 had significantly higher fat percentages and MR cows in lactation 1 had significantly higher protein percentages than LR cows. Associations for protein and fat composition were also found to be nonsignificant in the results of Nordlund et al. (1996) and Lombard et al. (2005), both using serum ELISA. From fecal culture tests, Donat et al. (2014) reported no association for fat percentage; however, those authors reported overall a reduced protein percentage associated with positive fecal culture cows, although in low-prevalence herds the opposite was found.

\section{Udder Health}

The results indicated that SCC (TD or lactational measures) and mastitis incidence were higher in HR compared with LR cows. These results were anticipated, as it would be expected that cows infected with MAP have a weakened immune system and therefore are more susceptible to udder infections. To support these results, higher mastitis incidences (Diéguez et al., 2008) and higher culling due to mastitis (Arrazuria et al., 2014) were found in affected herds when compared with negative herds. Also, in animals followed to slaughter, Merkal et al. (1975) observed that culling due to mastitis was greater in animals with subclinical paratuberculosis $(22.6 \%)$ compared with cows negative for paratuberculosis (3.6\%). In line with our results, other studies (McNab et al., 1991; Baptista et al., 2008) have found positive significant associations between SCC and paratuberculosis infection, but some have reported no association (Hendrick et al., 2005; Gonda et al., 2007) 


\section{Fertility}

In general, fertility traits were not significantly associated with risk group or clear trends were not apparent across the traits. Trends for DFS indicated that HR cows had longer DFS, whereas significant differences for NR56 and NINS implied that MR cows were more likely to return to service and require more inseminations to achieve conception than LR and HR cows. A MAP infection reduces absorption efficiency, and thus infected animals are liable to negative energy balance and might be expected to have lower fertility, as observed with other diseases (Fourichon et al., 2000). Likewise, Johnson-Ifearulundu et al. (2000) found that positive cows, on average, had a 28 -d increase in days open compared with ELISA-negative cows; however, results are not always so clear cut. For example, Sibley et al. (2012) found that CaI was longer during the interval the animal was tested positive, yet the effect on fertility was not seen in previous lactations to testing positive. Consequently, this could explain the lack of association found in our study, as an animal could have been categorized as HR based upon positive tests in a later lactation than the lactation considered in the comparison. Unexpected trends between risk groups were observed in other fertility studies (Gonda et al., 2007; Marcé et al., 2009; Smith et al., 2010), which sometimes suggested better fertility in infected cows. Often the farm policy, with HR cows in particular, would be to keep them until the end of their lactation but not to breed them again. It would be probable that a high proportion of test-positive cows might be withdrawn from service if they have already tested positive before their voluntary waiting period, which would bias the results reported here and in other studies.

\section{CONCLUSIONS}

The prevalence estimate of $76 \%$ of herds with at least 1 positive ELISA test leads us to conclude that MAP is important in terms of its extent, and measures should be applied to prevent further increase and also to protect those currently uninfected farms. Prevalence estimates are key to predict the effect of disease, and it is likely that earlier studies deemed there to be little economic incentive for farmers to put their efforts into controlling paratuberculosis in comparison with other cattle diseases because of its relatively low incidence (i.e., compared with mastitis). Our study provides information on how an entire lactation is affected at different levels of paratuberculosis risk for the first 3 lactations. A significant loss of milk production (904.4 $\mathrm{kg}$ ) over the first 3 lactations in HR cows was found compared with LR cows. Likewise, SCC and MAS incidence were higher in HR cows. Economic costs can be applied due to milk losses, penalty payments, and udder health problems, which can then be used to justify the control of the disease to farmers. These results, however, are expected to be underestimated due to the analysis design; nevertheless, they should demonstrate the importance that greater attention is given to control the disease, which would be aided by widespread testing.

\section{ACKNOWLEDGMENTS}

The authors acknowledge National Milk Records for providing the data as well as the assistance of colleagues Raphael Mrode and Georgios Banos (Scotland's Rural College, Edinburgh, UK). This research was funded by the Scottish Government Rural Affairs and the Environment Portfolio Strategic Research Programme 2011 to 2016 (Environmental Change Programme, Scotland, $\mathrm{UK})$.

\section{REFERENCES}

Aboagye, G., and M. T. Rowe. 2011. Occurrence of Mycobacterium avium ssp. paratuberculosis in raw water and water treatment operations for the production of potable water. Water Res. 45:32713278 .

Aly, S. S., R. J. Anderson, J. M. Adaska, J. Jiang, and I. A. Gardner. 2010. Association between Mycobacterium avium subspecies paratuberculosis infection and milk production in two California dairies. J. Dairy Sci. 93:1030-1040.

Anon. 2009. SB4022: An integrated strategy to determine the herd level prevalence of Johne's disease in the UK dairy herd. Accessed Mar. 12, 2012. http://archive.defra.gov.uk/foodfarm/farmanimal/ diseases/atoz/johnes/index.htm.

Arrazuria, R., I. Arnaiz, R. Fouz, C. Calvo, C. Eiras, and F. J. Dieguez. 2014. Association between Mycobacterium avium subsp paratuberculosis infection and culling in dairy cattle herds. Arch. Med. Vet. 46:39-44.

Baptista, F. M., S. S. Nielsen, and N. Toft. 2008. Association between the presence of antibodies to Mycobacterium avium subspecies paratuberculosis and somatic cell count. J. Dairy Sci. 91:109-118.

Barkema, H. W., J. W. Hesselink, S. L. McKenna, G. Benedictus, and H. Groenendaal. 2010. Global prevalence and economics of infection with Mycobacterium avium ssp. paratuberculosis in ruminants. Pages 10-21 in Paratuberculosis: Organism, Disease, Control. M. A. Behr and D. M. Collins, ed. CAB International, Wallingford, UK.

Bartlett, B., and H. Pearse. 2012. Integrating milk recording data and disease test results to provide a system for the management of paratuberculosis in UK dairy herds. In Proc. ICAR., May 28-June 1, 2012, Cork, Ireland. Accessed Oct. 25, 2016. http://www.icar. org/wp-content/uploads/2015/09/Bartlett.pdf.

Beasley, L., I. G. R. Truyers, D. J. Mellor, R. Norquay, S. Duthie, and K. A. Ellis. 2011. Prevalence of Johne's disease among cattle in Orkney. Vet. Rec. 169:50.

Benedictus, G., A. A. Dijkhuizen, and J. Stelwagen. 1987. Economic losses due to paratuberculosis in dairy cattle. Vet. Rec. 121:142146.

Benedictus, G., J. Verhoeff, Y. H. Schukken, and J. W. Hesselink. 2000. Dutch paratuberculosis programme history, principles and development. Vet. Microbiol. 77:399-413. 
Bennett, R., and J. Ijpelaar. 2005. Updated estimates of the costs associated with thirty four endemic livestock diseases in Great Britain: A note. J. Agric. Econ. 56:135-144.

Botsaris, G., B. M. C. Swift, I. Slana, M. Liapi, M. Christodoulou, M. Hatzitofi, V. Christodoulou, and C. E. D. Rees. 2016. Detection of viable Mycobacterium avium subspecies paratuberculosis in powdered infant formula by phage-PCR and confirmed by culture. Int. J. Food Microbiol. 216:91-94.

Carslake, D., W. Grant, L. E. Green, J. Cave, J. Greaves, M. Keeling, J. McEldowney, H. Weldegebriel, and G. F. Medley. 2011. Endemic cattle diseases: Comparative epidemiology and governance. Philos. Trans. R. Soc. Lond. B Biol. Sci. 366:1975-1986.

Cetinkaya, B., K. Egan, D. A. Harbour, and K. L. Morgan. 1996. An abattoir-based study of the prevalence of subclinical Johne's disease in adult cattle in south west England. Epidemiol. Infect. 116:373-379.

Çetinkaya, B., H. M. Erdogan, and K. L. Morgan. 1998. Prevalence, incidence and geographical distribution of Johne's disease in cattle in England and the Welsh borders. Vet. Rec. 143:265-269.

CHAWG. 2012. First annual report: GB cattle health and welfare group. Pages 1-48. Accessed Jan. 18, 2016. http://www.eblex.org. uk/wp/wp-content/uploads/2013/06/Cattle-Health-and-WelfareReport.pdf.

Diéguez, F. J., I. Arnaiz, M. L. Sanjuán, M. J. Vilar, and E. Yus. 2008. Management practices associated with Mycobacterium avium subspecies paratuberculosis infection and the effects of the infection on dairy herds. Vet. Rec. 162:614-617.

Donat, K., A. Soschinka, G. Erhardt, and H. R. Brandt. 2014. Paratuberculosis: Decrease in milk production of German Holstein dairy cows shedding Mycobacterium avium ssp. paratuberculosis depends on within-herd prevalence. Animal 8:852-858.

Fourichon, C., H. Seegers, and X. Malher. 2000. Effect of disease on reproduction in the dairy cow: A meta-analysis. Theriogenology $53: 1729-1759$

Gilmour, A. R., B. J. Gogel, B. R. Cullis, and R. Thompson. 2006. ASReml User Guide Release 2.0. VSN International Ltd., Hemel Hempstead, UK

Gonda, M. G., Y. M. Chang, G. E. Shook, M. T. Collins, and B. W. Kirkpatrick. 2007. Effect of Mycobacterium paratuberculosis infection on production, reproduction, and health traits in US Holsteins. Prev. Vet. Med. 80:103-119.

Grant, I. R., H. J. Ball, and M. T. Rowe. 2002. Incidence of Mycobacterium paratuberculosis in bulk raw and commercially pasteurized cows' milk from approved dairy processing establishments in the United Kingdom. Appl. Environ. Microbiol. 68:2428-2435.

Groenendaal, H., and F. J. Zagmutt. 2008. Scenario analysis of changes in consumption of dairy products caused by a hypothetical causal link between Mycobacterium avium subspecies paratuberculosis and Crohn's disease. J. Dairy Sci. 91:3245-3258.

Hendrick, S. H., D. F. Kelton, K. E. Leslie, K. D. Lissemore, M. Archambault, and T. F. Duffield. 2005. Effect of paratuberculosis on culling, milk production, and milk quality in dairy herds. J. Am. Vet. Med. Assoc. 227:1302-1308.

Hoogendam, K., E. Richardson, and J. Mee. 2009. Paratuberculosis sero-status and milk production, SCC and calving interval in Irish dairy herds. Ir. Vet. J. 62:265-271.

Johnson, Y. J., J. B. Kaneene, J. C. Gardiner, J. W. Lloyd, D. J. Sprecher, and P. H. Coe. 2001. The effect of subclinical Mycobacterium paratuberculosis infection on milk production in Michigan Dairy cows. J. Dairy Sci. 84:2188-2194.

Johnson-Ifearulundu, Y. J., J. B. Kaneene, D. J. Sprecher, J. C. Gardiner, and J. W. Lloyd. 2000. The effect of subclinical Mycobacterium paratuberculosis infection on days open in Michigan, USA, dairy cows. Prev. Vet. Med. 46:171-181.

Kirkeby, C., K. Græsbøll, T. Halasa, N. Toft, and S. S. Nielsen. 2015. Mean effective sensitivity for Mycobacterium avium ssp. paratuberculosis infection in cattle herds. BMC Vet. Res. 11:190.

Kudahl, A., S. S. Nielsen, and J. T. Sorensen. 2004. Relationship between antibodies against Mycobacterium avium ssp. paratuberculosis in milk and shape of lactation curves. Prev. Vet. Med. 62:119-134.
Lombard, J. E., I. A. Gardner, S. R. Jafarzadeh, C. P. Fossler, B. Harris, R. T. Capsel, B. A. Wagner, and W. O. Johnson. 2013. Herd-level prevalence of Mycobacterium avium ssp. paratuberculosis infection in United States dairy herds in 2007. Prev. Vet. Med. 108:234-238

Lombard, J. E., F. B. Garry, B. J. McCluskey, and B. A. Wagner. 2005. Risk of removal and effects on milk production associated with paratuberculosis status in dairy cows. J. Am. Vet. Med. Assoc. 227:1975-1981.

Marcé, C., F. Beaudeau, N. Bareille, H. Seegers, and C. Fourichon. 2009. Higher non-return rate associated with Mycobacterium avium subspecies paratuberculosis infection at early stage in Holstein dairy cows. Theriogenology 71:807-816.

McNab, W. B., A. H. Meek, S. W. Martin, and J. R. Duncan. 1991 Associations between dairy production indices and lipoarabinomannan enzyme-immunoassay results for paratuberculosis. Can. J. Vet. Res. 55:356-361.

Merkal, R. S., A. B. Larsen, and G. D. Booth. 1975. Analysis of the effect of inapparent bovine paratuberculosis. Am. J. Vet. Res. $36: 837-838$.

Molodecky, N. A., I. S. Soon, D. M. Rabi, W. A. Ghali, M. Ferris, G. Chernoff, E. I. Benchimol, R. Panaccione, S. Ghosh, H. W. Barkhema, and G. G. Kaplan. 2012. Increasing incidence and prevalence of the inflammatory bowel diseases with time, based on systematic review. Gastroenterology 142:46-54.

Naser, S. A., S. Thanigachalam, C. T. Dow, and M. T. Collins. 2013. Exploring the role of Mycobacterium avium subspecies paratuberculosis in the pathogenesis of type 1 diabetes mellitus: A pilot study. Gut Pathog. 5:14.

Nielsen, S. S. 2007. Danish control programme for bovine paratuberculosis. Cattle Pract. 15:161-168.

Nielsen, S. S., and A. K. Ersbøll. 2006. Age at occurrence of Mycobacterium avium subspecies paratuberculosis in naturally infected dairy cows. J. Dairy Sci. 89:4557-4566.

Nielsen, S. S., M. A. Krogh, and C. Enevoldsen. 2009. Time to the occurrence of a decline in milk production in cows with various paratuberculosis antibody profiles. J. Dairy Sci. 92:149-155.

Nielsen, S. S., and N. Toft. 2009. A review of prevalences of paratuberculosis in farmed animals in Europe. Prev. Vet. Med. 88:1-14.

Nordlund, K. V., W. J. Goodger, J. Pelletier, and M. T. Collins. 1996 Associations between subclinical paratuberculosis and milk production, milk components, and somatic cell counts in dairy herds. J. Am. Vet. Med. Assoc. 208:1872-1876.

Pritchard, T., M. Coffey, R. Mrode, and E. Wall. 2013. Genetic parameters for production, health, fertility and longevity traits in dairy cows. Animal 7:34-46.

Raizman, E. A., J. P. Fetrow, and S. J. Wells. 2009. Loss of income from cows shedding Mycobacterium avium subspecies paratuberculosis prior to calving compared with cows not shedding the organism on two Minnesota dairy farms. J. Dairy Sci. 92:4929-4936.

Rani, P. S., L. A. Sechi, and N. Ahmed. 2010. Mycobacterium avium ssp. paratuberculosis as a trigger of type-1 diabetes: Destination Sardinia, or beyond? Gut Pathog. 2:1.

Richardson, E., and S. More. 2009. Direct and indirect effects of Johne's disease on farm and animal productivity in an Irish dairy herd. Ir. Vet. J. 62:526-532.

Rubery, E. 2001. A review of the evidence for a link between exposure to Mycobacterium paratuberculosis (MAP) and Crohn's disease (CD) in humans. Pages 1-70 in A Report for the Food Standards Agency. University of Cambridge, Cambridge, UK

Sartor, R. B. 2005. Does Mycobacterium avium subspecies paratuberculosis cause Crohn's disease? Gut 54:896-898.

SAS Institute. 2006. SAS/STAT Software. Release 9.1, SAS Institute Inc., Cary, NC.

Sibley, R. J., P. J. Orpin, and H. L. Pearse. 2012. Fertility, udder health and milk production in cows that have high milk antibodies to paratuberculosis. Pages 194-195 In Proc. of the 11th International Colloquium on Paratuberculosis, February 5-10 2012, Sydney, Australia International Association for Paratuberculosis. Curran Associates Inc., New York, NY. 
Slana, I., R. Pribylova, A. Kralova, and I. Pavlik. 2011. Persistence of Mycobacterium avium ssp. paratuberculosis at a farm-scale biogas plant supplied with manure from paratuberculosis-affected dairy cattle. Appl. Environ. Microbiol. 77:3115-3119.

Smith, R. L., Y. T. Grohn, A. K. Pradhan, R. H. Whitlock, J. S. Van Kessel, J. M. Smith, D. R. Wolfgang, and Y. H. Schukken. 2009. A longitudinal study on the impact of Johne's disease status on milk production in individual cows. J. Dairy Sci. 92:2653-2661.

Smith, R. L., R. L. Strawderman, Y. H. Schukken, S. J. Wells, A. K. Pradhan, L. A. Espejo, R. H. Whitlock, J. S. Van Kessel, J. M. Smith, D. R. Wolfgang, and Y. T. Gröhn. 2010. Effect of Johne's disease status on reproduction and culling in dairy cattle. J. Dairy Sci. 93:3513-3524.

Sorge, U. S., K. Lissemore, A. Godkin, S. Hendrick, S. Wells, and D. Kelton. 2011. Associations between paratuberculosis milk ELISA result, milk production, and breed in Canadian dairy cows. J. Dairy Sci. 94:754-761.

Spangler, E., S. Bech-Nielsen, and L. E. Heider. 1992. Diagnostic performance of two serologic tests and fecal culture for subclinical paratuberculosis, and associations with production. Prev. Vet. Med. 13:185-195.

Stott, A. W., G. M. Jones, R. W. Humphry, and G. J. Gunn. 2005. Financial incentive to control paratuberculosis (Johne's disease) on dairy farms in the United Kingdom. Vet. Rec. 156:825-831.

Tiwari, A., J. A. VanLeeuwen, I. R. Dohoo, G. P. Keefe, J. P. Haddad, R. Tremblay, H. M. Scott, and T. Whiting. 2007. Production ef- fects of pathogens causing bovine leukosis, bovine viral diarrhea paratuberculosis, and neosporosis. J. Dairy Sci. 90:659-669.

Uzoigwe, J. C., M. L. Khaitsa, and P. S. Gibbs. 2007. Epidemiological evidence for Mycobacterium avium subspecies paratuberculosis as a cause of Crohn's disease. Epidemiol. Infect. 135:1057-1068.

Wall, E., S. Brotherstone, J. F. Kearney, J. A. Woolliams, and M. P. Coffey. 2005. Impact of non additive genetic effects in the estimation of breeding values for fertility and correlated traits. J. Dairy Sci. 88:376-385.

Whitlock, R. H., and C. Buergelt. 1996. Preclinical and clinical manifestations of paratuberculosis (including pathology). Vet. Clin. North Am. Food Anim. Pract. 12:345-356.

Whittington, R. J., D. J. Marshall, P. J. Nicholls, I. B. Marsh, and L. A. Redacliff. 2004. Survival and dormancy of Mycobacterium avium ssp. paratuberculosis in the environment. Appl. Environ. Microbiol. 70:2989-3004.

Windsor, P. A., and R. J. Whittington. 2010. Evidence for age susceptibility of cattle to Johne's disease. Vet. J. 184:37-44.

Woodbine, K. A., Y. H. Schukken, L. E. Green, A. Ramirez-Villaescusa, S. Mason, S. J. Moore, C. Bilbao, N. Swann, and G. F. Medley. 2009. Seroprevalence and epidemiological characteristics of $\mathrm{Myco}$ bacterium avium ssp. paratuberculosis on 114 cattle farms in south west England. Prev. Vet. Med. 89:102-109. 